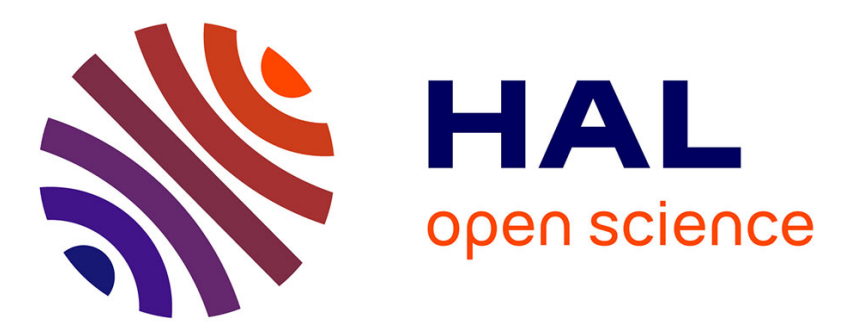

\title{
Emergent technologies for inter-enterprises collaboration and business evaluation
}

Ibrahim Benali, Baudouin Dafflon, Mohand Lounes Bentaha, Néjib Moalla

\section{To cite this version:}

Ibrahim Benali, Baudouin Dafflon, Mohand Lounes Bentaha, Néjib Moalla. Emergent technologies for inter-enterprises collaboration and business evaluation. 11th IEEE International Conference on Software, Knowledge, Information Management and Applications (SKIMA 2017), Dec 2017, Malabe, Sri Lanka. pp.1-5, 10.1109/SKIMA.2017.8294094 . hal-01963192

\section{HAL Id: hal-01963192 \\ https://hal.science/hal-01963192}

Submitted on 22 Nov 2019

HAL is a multi-disciplinary open access archive for the deposit and dissemination of scientific research documents, whether they are published or not. The documents may come from teaching and research institutions in France or abroad, or from public or private research centers.
L'archive ouverte pluridisciplinaire $\mathbf{H A L}$, est destinée au dépôt et à la diffusion de documents scientifiques de niveau recherche, publiés ou non, émanant des établissements d'enseignement et de recherche français ou étrangers, des laboratoires publics ou privés. 
archives-ouvertes

\title{
Emergent technologies for inter-enterprises collaboration and business evaluation
}

\author{
Ibrahim Benali, Baudouin Dafflon, Mohand Lounes Bentaha, Néjib Moalla
}

\section{To cite this version:}

Ibrahim Benali, Baudouin Dafflon, Mohand Lounes Bentaha, Néjib Moalla. Emergent technologies for inter-enterprises collaboration and business evaluation. 11th IEEE International Conference on Software, Knowledge, Information Management and Applications (SKIMA 2017), Dec 2017, Malabe, Sri Lanka. pp.1-5, 10.1109/SKIMA.2017.8294094 . hal-01963192

\section{HAL Id: hal-01963192 \\ https://hal.archives-ouvertes.fr/hal-01963192}

Submitted on 22 Nov 2019

HAL is a multi-disciplinary open access archive for the deposit and dissemination of scientific research documents, whether they are published or not. The documents may come from teaching and research institutions in France or abroad, or from public or private research centers.
L'archive ouverte pluridisciplinaire HAL, est destinée au dépôt et à la diffusion de documents scientifiques de niveau recherche, publiés ou non, émanant des établissements d'enseignement et de recherche français ou étrangers, des laboratoires publics ou privés. 


\title{
Emergent technologies for Inter-enterprises collaboration and business evaluation
}

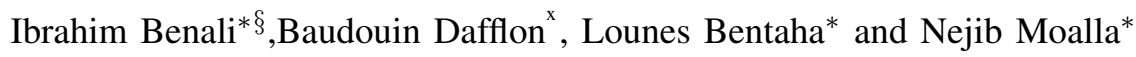 \\ * Lumière Lyon 2 University \\ x Claude Bernard Lyon 1 University \\ $\S$ Etablissements TARDY
}

\begin{abstract}
Conventional manufacturing systems are designed for intra-enterprise process management, and they hardly handle processes with tasks using extra-enterprise boundaries data. Besides, inter-enterprise collaboration and new IT enablers for industry 4.0 are becoming a highly topical issue to study, due to : (a) The emergence of new technologies mainly Internet of Things, big data processing and Cyber-Physical systems (b) The new customers' needs that face the SMEs.

Many constraints and issues have to be taken into account before establishing Inter-enterprises collaboration, namely: The product information, the business processes and the heterogeneous data. Moreover, the exponential growth of data coming from all the enterprises causes several challenges regarding their exploitation.

In this context, this study is interested in Big Data capabilities to help Small and Medium Enterprises to find out more lurking opportunities. We have focus on the combination between emergent IT technologies, mainly Big Data, and inter-interprises collaboration in order to provide an added value. The result of this study is a new approach, that could be adapted by SMEs, for new project evaluation within a network of enterprises.
\end{abstract}

Keywords: Industry 4.0, Collaboration, Inter-enterprise collaboration, Business evaluation, Big Data, Manufacturing, IT technologies.

\section{INTRODUCTION}

Today's manufacturing is going through the fourth industrial revolution. The term industry 4.0 has been first introduced in 2011 at the Hannover Fair in Germany, it mainly involves technological innovations applied to production processes in the field of automation, control and information technologies (Hermann et al. 2016). This revolution focuses on a range of new technologies that combine the physical, digital and biological worlds (Marr 2016). These technologies are able to connect more people to the web, enhance the productivity of businesses and help to generate new assets. Also, technologies have today achieved a certain maturity which is potentially capable of changing the way to monitor, supervise and decide in the manufacturing field.

Emerging technology breakthroughs in several fields, such as: Internet of Things, artificial intelligence, robotics, CyberPhysical Systems and big data, enable companies to adapt themselves to emergent customers needs and unplanned changes, to schedule maintenance and to predict failures (Jazdi 2014). Thus, companies step forward towards the implementation of industry 4.0.
Therefore, and in order to stay competitive, companies are moving from a traditional system to a more intelligent system in order to improve their productive capacity and their value proposition. They are moving towards exploring the opportunities and facilities afforded by the above mentioned technologies. The path of collaborating and exploit the data of a network of enterprises seems to be a valuable solution to face multi-nationals and stay in the market. Thus, enterprises are looking for a new way to make the growing industrial data as a new resource which could create new opportunities, new innovative products or new services.

According to $\mathrm{ICD}^{1}$, the size of data is increasing immeasurably and doubling each year. It will reach about 44 zettabytes by 2020 and data set that seems large at the present time, will almost certainly seem small in the near future (MIT Technology Review 2013).

Moreover, Big data technologies need to support the volume, velocity, variety, veracity, and variability, to perform several processing and to provide scalable storages (Anagnostopoulos et al. 2016). On the other hand, from these needs, (Sivarajah et al. 2017) group big data challenges into three main categories :

1) Data challenges: Relating to the $5 \mathrm{OR} 6 \mathrm{Vs}$ (depending on the definitions of each V).

2) Process challenges: Relating to the methods and techniques of collecting, organizing and analyzing data.

3) Management challenges: Relating to the ethical aspects and access rights such as privacy and security.

Companies can profit from several benefits of using big data for industry in terms of understandings customers' needs, future issues anticipation, market development, decision-making, etc.(Yin et al. 2015).

Besides, companies are looking for how to face continuous and varying changes. As a solution, synergy and collaboration between different enterprises presents an efficient way to effectively overcome these issues(Vargas et al. 2016). However, some of collaboration processes are very complex due to : product information included in CAD files, variability of engineering and business processes, heterogeneous softwares, etc.(Domazet 2000).

Aware of all these constraints, supporting manufacturing

${ }^{1}$ Data Growth, Business Opportunities, and the IT Imperatives: https://www.emc.com/leadership/digital-universe/2014iview/executivesummary.htm 
industries presents a major issue. Actually, it enables collaboration and data sharing in a better way in order to accelerate some tedious processes and face the new and variable customers' needs.

To provide a first solution to this problem, this paper proposes a new approach for enterprise collaboration and business evaluation. In this context, the paper is organized as follow: Section II presents a review of the techniques used for inter-enterprise collaboration and the advanced technologies used for moving towards industry 4.0. Secondly, a global view of the proposed approach is presented. In section III and IV, an application of our approach in the context of two enterprises working in different sectors (metal and plastic) is proposed.

\section{RELATED WORK}

This section is dedicated to give a clearer idea about the inter-enterprise collaboration backgrounds on the one hand. On the other hand, the main industry 4.0 technological enablers have been introduced. The choice of adopting this procedure of approaching the matter is due to the lack of works that deal with both technological enablers and business evaluation.

\section{A. Inter-enterprise collaboration background}

Implementing industry 4.0 will drive enterprises to set up new partnerships, with other enterprises from other sectors, in order to fit customers' requirements quickly (Kagermann et al. 2013). Thus, working within a network of businesses will be highly recommended rather than working alone in a single company.

Besides, in order to cooperate between business partners, a new system should be developed in order to connect customers, systems, suppliers and products to each other. Thereby, enterprises could work jointly and synchronously on several projects regardless of their location.

The collaboration, in a basic way, is established through emails, phone calls, chat, shared documents etc.(Kolberg et al. 2013). However, the emerging intelligent manufacturing systems within the industry 4.0 are based on real-time interaction, flexible and customized production, resource efficiency, etc. And could be reached through some emergent and new advanced technologies.

Before and after the appearance of industry 4.0, several researches have been done in order to address the topic of inter-enterprise collaboration. Also, it is worth mentioning that this topic, in most cases, have been addressed by means of ontological modeling.

For instance, (Lin et al. 2007) develop a manufacturing system engineering (MSE) using the Semantic Web technology in order to facilitate information exchange between several enterprises in a flexible way. In fact, they do not have to change any of their existing terminology or practices. On the other hand, they have to move all their knowledge in a specific format to the MSE. This tedious and manual method represent a big limitation of this system which bas to be automated using new advanced technologies. Furthermore,
(Lee et al. 2009) propose a product ontology architecture in order to share products' semantics with other enterprises and achieve interoperability between them.

Other solutions have been proposed aside from ontological modeling:

(Sakarya et al. 2012) suggest doing social and business alliances between actors from different sectors. Enterprises can choose a collaborative strategy rather than a go-italone strategy. Thus, they need to share resources, core competencies and know-how in order to face, together, new needs. (Kolberg et al. 2013) approach the need of a federated real-time collaboration platform. They present a new framework called ConnectedSpaces which consider spaces, views, information and communication resources, semantic processing and other features in order to achieve a certain level of collaboration. (Vargas et al. 2016) develop a conceptual model based on inter-enterprise architecture which can be used by a collaborative network to handle unexpected events coming from hierarchical production planning. Their approach will help decision makers to better understand information about the complexity of the new events in order to make efficient decisions.

\section{B. IT enablers for industry 4.0}

The growing demand and the complexity of the new product are always considered as the big challenges for the enterprises. Each product follows the industrialization process through several steps before the launch on the market

- Requirements definition

- Feasibility analysis and conception

- Business analysis : return on investment, budget, strategy and so on.

- Creation of the quotation

- Production

- Quality control

- etc.

Each of these steps can be considered as very time consuming, especially for complex, multi-physical or large size products.

Besides, enterprises are looking for a new and innovative way to shorten or automatize some of these steps in order to enhance the responsiveness regarding customers. However, the question arises how (SMEs) Small and Medium Enterprises can exploit emergent technologies such as : big data, machine learning, cyber-physical systems, servitization, etc. in order to generate a valuable value which can impact all aspects of industrialization ?

In this context, several researches have been done using these technologies with "Big Data" as a main focus. (Naeem et al. 2015) introduced a four layers framework which help enterprises to take advantage of intangible resources. Multisources data such as : Enterprise Resource Planning (ERP), Supplier Relationship Management (SRM), Product Life Cycle Management (PLM) and Customer Relationship Management (CRM) have been used. Their approach is based on a "Big Data" perspective, they could help enterprises to find 
out hidden opportunities and other information that could support decision-making. (Stojanovic et al. 2016) developed a scalable system for data-driver quality control. The system is composed of six layers and aims to detect anomalies that can appear during the manufacturing processes in a big data and real-time approach. The data are collected during the detection phase, processed (real-time and batch), analyzed using some machine learning and Complex Event Processing (CEP) implementations and finally presented to the user who can interact with it. Also, the system covers the security and integration aspects. (Santos et al. 2017) propose a seven layers architecture using big data technologies. The aim of their work is to deal with all existing data in a factory, from the collection to the exploitation, in order to support decision-making and help to understand the business at a more atomic level. Though, the architecture is under implementation and may need some enhancements.

In addition to big data, services are more and more adopted due to their benefits. (Marini et al. 2016) discussed a Data as a Service approach in a Big Data perspective. Their approach aims to monitor a cyber-physical production system (CPPS). It can collect data from the machine fleet using sensors and other machine controls, clean it and prepare it for further exploitation. In fact, It's a first step towards a full-fledged architecture for CPPS.

\section{COLlABORATIVE FRAMEWORK FOR BUSINESS OPPORTUNITIES EVALUATION}

Data is becoming a valuable tool for the industry that can help enterprises to detect a lot of opportunities and to gather relevant recommendations. although advanced IT technologies have shown their ability to exploit and to transform these data into a useful value, recent researches revealed some challenges related to the big data 5Vs : Volume, velocity, variety, veracity and variability.

In this context, our contribution aims to use all existing industrial data in two or more enterprises from different sector in order to build a system which is able to analyze future projects from two different perspectives: technical and business.

As shown in figure 1, the idea is to take advantage of the collaborative network, gather the know-how of all enterprises, complement each other and face the new customers' needs in a win-win strategy.

The framework is based on a network of enterprises from which data will be collected, cleaned, organized and analyzed. At this step, a particular format of resulted data is needed in order to facilitate future interactions. Once the data is formated, some enrichments can be performed in order to have a more complete model. This model will receive new projects as input and provide recommendations and a project evaluation as output.

Indeed, the challenge here is not very common. Each enterprise has her own softwares : ERP, CRM, SRM, etc., her specific sensors or CPPSs and her particular industrialization phases. Multiple techniques and/or methods are needed to build a new architecture which can ensure an efficient data

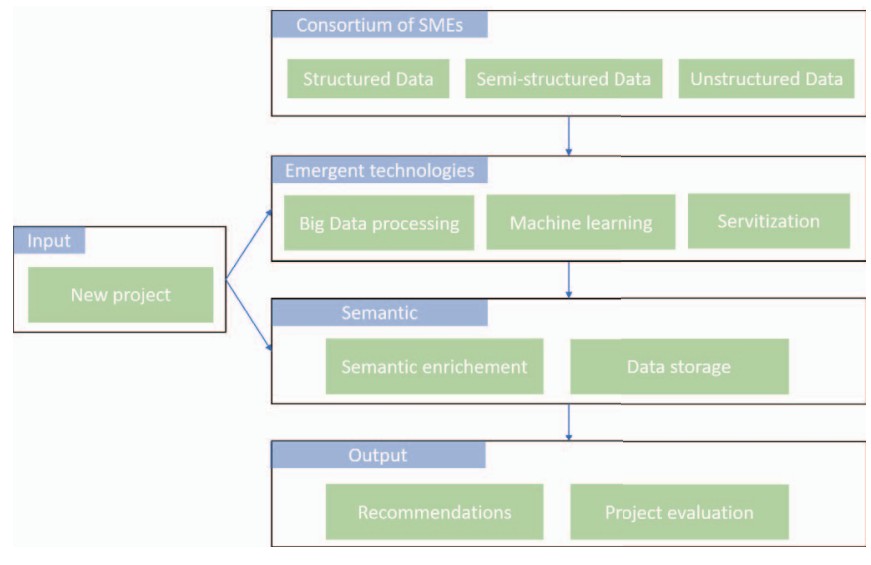

Fig. 1. Conceptual layout of the proposed framework.

extraction, data processing, data analytics and overcome all problems related to latency or bandwidth.

As a first stage, we will focus on the collaboration of two manufacturing company from different sectors : metal and plastic.

\section{APPLICATION}

We performed the implementation of the proposed approach in the context of two SMEs namely APR and TARDY. The first company is specialized in plastic manufacturing and deals with small to medium plastic products. The second company is specialized in metal manufacturing and deals with medium to large metal products. They both aim to integrate new technologies in order to enhance their know-how and the responsiveness regarding the customers' demands.

When they receive a request from a customer, they have to analyze its feasibility, its viability and then send a quotation to the customer. The incoming project are generally in form of e-mail or STEP file (ISO 10303 which represent Computer-aided design (CAD) 3D objects.). Thereby, the first step is to collect data from different sources :

- Existing features in the STEP.

- Data from CPPSs (production system data).

- Data from ERP, CRM, etc. (information system data).

This study will focus on the translation of the various data into set of big data enablers designed for collaboration and project evaluation. In fact, several researches have addressed the problem of features extraction from a STEP file. But there is still a need to a mechanism which can transform a STEP file into a readable or neutral format.

As a result, the figure 2 depicts an application of the framework. Extracted data is subjected to real-time and batch processing in order to clean, organize and analyze data using big data technologies (such as: Hadoop, ETL, Storm, etc.) and machine learning algorithms. Some of this data will feed learning algorithms (such as: Linear Regression, SVM, Deep Learning, etc.) which lead on to a model that will be applied on future data. Several iterations could lead to several models which will be improved through several iterations. Finally, features from incoming projects will request the 
model about feasibility, viability and recommendations based on the large accumulated volume of data as a result of old accepted/rejected projects. Recommendations will be stored in order to support the decision-making process.

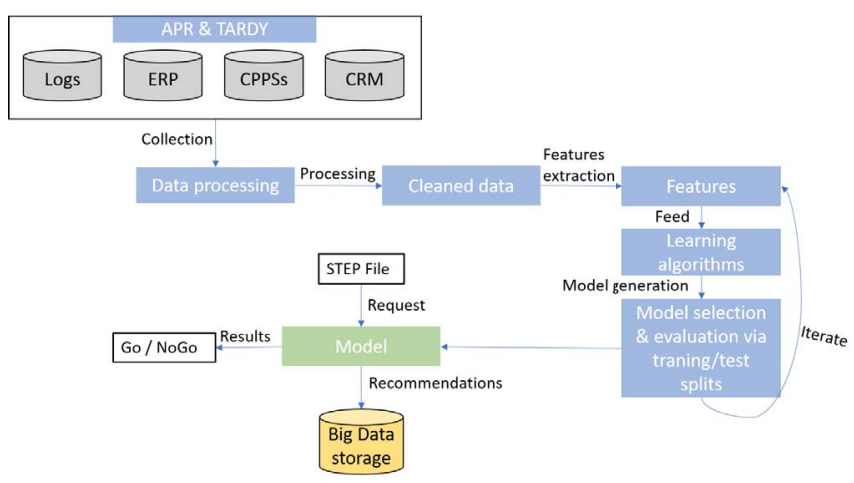

Fig. 2. Proposed solution

From a scientific point of view, the architecture arises several questions and challenges :

- How to create useful value using various data from two different sectors?

- Which are the techniques and methods that could be reused or tailored to fit in this architecture ?

- How to transform all the data into a enterprise assets ?

- How to use this assets to find other lurking opportunities

From a technical point of view, several solutions are known for their ability to process versatile voluminous data such as : Hadoop and Spark. Hadoop is known for parallel and batch processing. On the other hand, Spark is known for fast and real-time big data processing. Also, it provides several libraries to structure data and perform machine learning algorithms on it. (Anagnostopoulos et al. 2016) provide the following table (figure 3 ) with the main Hadoop-based solutions and their characteristics :

However, from comparative literature studies, the revealed issue is that there is no evidence for when any one of this solutions needs to be preferred over the others.

\section{CONCLUSION}

Implementing industry 4.0 is a step forward towards innovation in the manufacturing field. In fact, leveraging advanced IT technologies will enhance productivity, performance and know-how of companies.

In this paper, backgrounds of the inter-enterprises collaboration and technological enablers for industry 4.0 have been presented. This includes the importance of collaboration and the benefits that data exploitation could provide. On the other hand, in the context of automated project evaluation, limited work has been carried out with the focus on big data and inter-enterprises collaboration.

The authors of this paper have proposed a new framework of inter-enterprise collaboration with the aim of performing jointly new projects and benefiting from the know-how of all the network.

\begin{tabular}{|c|c|c|c|c|}
\hline \multirow[t]{2}{*}{ Platforms } & \multicolumn{4}{|c|}{ Characteristics } \\
\hline & $\begin{array}{l}\text { Real-time } \\
\text { analytics }\end{array}$ & $\begin{array}{l}\text { Data } \\
\text { integration }\end{array}$ & Open source & Application domain \\
\hline Pentaho & $\sqrt{ }$ & $\sqrt{ }$ & & Business analytics \\
\hline Mahoot & & & $\sqrt{ }$ & $\begin{array}{l}\text { Data mining, machine learning } \\
\text { algorithms }\end{array}$ \\
\hline ML-Hadoop & & & $\sqrt{ }$ & $\begin{array}{l}\text { Data mining, machine learning } \\
\text { algorithms }\end{array}$ \\
\hline Hive & & $\sqrt{ }$ & $\sqrt{ }$ & $\begin{array}{l}\text { MapReduce-based large data set } \\
\text { analysis }\end{array}$ \\
\hline Pig & & $\sqrt{ }$ & $\sqrt{ }$ & $\begin{array}{l}\text { MapReduce-based large-scale } \\
\text { parallel implementations }\end{array}$ \\
\hline Storm & $\sqrt{ }$ & & $\sqrt{ }$ & $\begin{array}{l}\text { Real-time analytics, online } \\
\text { machine learning, continuous } \\
\text { computation, distributed } \\
\text { extraction-transformation- } \\
\text { loading (ETL) } \\
\text { processes }\end{array}$ \\
\hline Spark & $\sqrt{ }$ & $\sqrt{ }$ & $\sqrt{ }$ & $\begin{array}{l}\text { Large-scale real-tine data } \\
\text { processing, scalaole machine } \\
\text { learning applications }\end{array}$ \\
\hline Sqoop & & $\sqrt{ }$ & $\sqrt{ }$ & $\begin{array}{l}\text { Transfers bulk data between } \\
\text { Apache Hadoop and structured } \\
\text { datastores (RDBMS) }\end{array}$ \\
\hline Flume & & $\sqrt{ }$ & $\sqrt{ }$ & $\begin{array}{l}\text { Efficient collection aggregation, } \\
\text { and transfers of large amounts } \\
\text { of log data }\end{array}$ \\
\hline Zookeeper & & $\sqrt{ }$ & $\sqrt{ }$ & $\begin{array}{l}\text { Reliable and efficient distributed } \\
\text { coordination in d.stributed } \\
\text { applications }\end{array}$ \\
\hline
\end{tabular}

Fig. 3. Hadoop-based platforms according to their main characteristics and their big data application domain

An application of this approach was presented but it is still under real implementation and is subjected to future enhancements.

\section{ACKNOWLEDGEMENT}

This work is supported by a CIFRE convention (2017 / 0224) of the ANRT from the French Ministry of Higher Education and Research and "Les Etablissements TARDY".

\section{REFERENCES}

Hermann, Mario, Tobias Pentek, and Boris Otto (2016). "Design principles for industrie 4.0 scenarios." In: System Sciences (HICSS), 2016 49th Hawaii International Conference on. IEEE, pp. 3928-3937.

Marr, Bernard (2016). Why Everyone Must Get Ready For The 4th Industrial Revolution? Forbes (Blog).

Jazdi, Nasser (2014). "Cyber physical systems in the context of Industry 4.0." In: Automation, Quality and Testing, Robotics, 2014 IEEE International Conference on. IEEE, pp. 1-4.

MIT Technology Review (2013). The Big Data Conundrum: How to Define It? https : / / www . technologyreview. com/s/519851/the-bigdata-conundrum-how-to-define-it/. MIT.

Anagnostopoulos, Ioannis, Sherali Zeadally, and E Exposito (2016). "Handling big data: research challenges and future directions." In: The Journal of Supercomputing 72.4, pp. $1494-1516$.

Sivarajah, Uthayasankar et al. (2017). "Critical analysis of Big Data challenges and analytical methods." In: Journal of Business Research 70, pp. 263-286. 
Yin, Shen and Okyay Kaynak (2015). "Big data for modern industry: challenges and trends [point of view]." In: Proceedings of the IEEE 103.2, pp. 143-146.

Vargas, Alix et al. (2016). "Inter-enterprise architecture as a tool to empower decision-making in hierarchical collaborative production planning." In: Data \& Knowledge Engineering 105, pp. 5-22.

Domazet, Dragan (2000). "Enabling engineering collaboration in inter-enterprise design chains using collaborative agents." In: SIMTech technical report.

Kagermann, H, W Wahlster, and Helbig J (2013). "Recommendations for implementing the strategic initiative Industrie 4.0.” In: pp. 13-78.

Kolberg, Mario et al. (2013). "Feature interaction in a federated communications-enabled collaboration platform." In: Computer Networks 57.12, pp. 2410-2428.

Lin, HK and Jenny A Harding (2007). "A manufacturing system engineering ontology model on the semantic web for inter-enterprise collaboration." In: Computers in Industry 58.5, pp. 428-437.

Lee, Jeongsoo et al. (2009). "Design of product ontology architecture for collaborative enterprises." In: Expert Systems with Applications 36.2, pp. 2300-2309.

Sakarya, Sema et al. (2012). "Social alliances: Business and social enterprise collaboration for social transformation." In: Journal of Business Research 65.12, pp. 1710-1720.

Naeem, Muhammad et al. (2015). "Opportunity Analysis for Enterprise Collaboration between Networks of SMEs." In: IWEI Workshops.

Stojanovic, Ljiljana et al. (2016). "Big-data-driven anomaly detection in industry (4.0): An approach and a case study." In: Big Data (Big Data), 2016 IEEE International Conference on. IEEE, pp. 1647-1652.

Santos, Maribel Yasmina et al. (2017). “A Big Data Analytics Architecture for Industry 4.0." In: World Conference on Information Systems and Technologies. Springer, pp. 175184.

Marini, Alessandro and Devis Bianchini (2016). "Big Data As A Service For Monitoring Cyber-Physical Production Systems." In: ECMS, pp. 579-586. 